\title{
Multisystemic Cryptococcal Infection in an Immunocompetent Child
}

\author{
Gurdeep S. Dhooria ${ }^{1}$ (D) Deepak Bhat ${ }^{1} \cdot$ Shruti Kakkar $^{1}$
}

Received: 5 May 2020 / Accepted: 23 June 2020 / Published online: 2 July 2020

(C) Dr. K C Chaudhuri Foundation 2020

To the Editor: Cryptococcus neoformans causes infection most commonly in immunocompromised patients, including HIV positive [1]. We describe here a case of disseminated cryptococcal infection in an immunocompetent child without any comorbidity.

A 5-year-old boy presented with fever since 3 mo, abdominal distension and weight loss since 1 mo. There was no history of prolonged cough, contact with tuberculosis, or any chronic illness. There was exposure to pigeon droppings in house. He had mild pallor, icterus with edema feet with bilateral cervical lymphadenopathy. Multiple papules with central umbilication were seen over face. Abdomen was distended with firm hepatosplenomegaly and ascites. Eye examination revealed left choroiditis.

Investigations showed leucocytosis with raised ESR and Creactive protein. Tuberculin test was negative. Chest X-ray showed minimal right pleural effusion. CBNAAT test for Mycobacterium tuberculosis from gastric aspirate and lymph node biopsy were negative. Workup for immunodeficiency disorders revealed normal CD4 (26.4\%) and CD8 (43.64\%) subsets, normal immunoglobulin levels and negative HIV infection. Serological tests for tropical infections were negative.

Cervical lymph node and bone marrow showed numerous foamy macrophages, within which spores of Cryptococcus (highlighted on PAS stain) were seen. CSF India ink stain showed encapsulated budding yeast cells suggestive of Cryptococcus neoformans. CSF Cryptococcal antigen was also positive. Blood and CSF cultures showed no growth. Since the child had Cryptococcal infection with multisystemic involvement, he was started on deoxycholate Amphotericin B $(1 \mathrm{mg} / \mathrm{kg} / \mathrm{d})$ and Flucytosine $(100 \mathrm{mg} / \mathrm{kg} / \mathrm{d})$. Patient showed resolution of fever, skin and eye lesions, and regression of hepatosplenomegaly and was discharged on oral

Gurdeep S. Dhooria

gurdeep2005123@gmail.com
Fluconazole (consolidation for $8 \mathrm{wk}: 12 \mathrm{mg} / \mathrm{kg} / \mathrm{d}$; maintenance for $12 \mathrm{mo}: 6 \mathrm{mg} / \mathrm{kg} / \mathrm{d})$ [2].

Cryptococcus neoformans is a ubiquitous, yeast like infection occurring via respiratory route and results in hematogenous spread, CNS being the most affected site. The systemic form is defined as involvement of two or more non-adjacent areas [3]. The skin lesions mimicking extensive molluscum contagiosum are seen in 10-20\% cases and are considered marker of disseminated disease [4]. Differential diagnoses of Cryptococcosis include tuberculosis, malignancies and other fungal infections [5]. Although uncommon in immunocompetent person, Cryptococcal infection can have a multisystemic involvement as is highlighted in this case.

\section{Compliance with Ethical Standards}

Conflict of Interest None.

\section{References}

1. Beardsley J, Sorrell TC, Chen SC-A. Central nervous system cryptococcal infections in non-HIV infected patients. J Fungi (Basel). 2019;5:71.

2. Perfect JR, Dismukes WE, Dromer F, et al. Clinical practice guidelines for the management of cryptococcal disease: 2010 update by the Infectious Diseases Society of America. Clin Infect Dis. 2010;50: 291-322.

3. Valente ES, Lazzarin MC, Koech BL, et al. Disseminated cryptococcosis presenting as cutaneous cellulitis in an adolescent with systemic lupus erythematosus. Infect Dis Rep. 2015;7:5743.

4. Hayashida MZ, Seque CA, Pasin VP, Enokihara MMSES, Porro AM. Disseminated cryptococcosis with skin lesions: report of a case series. An Bras Dermatol. 2017;92:69-72.

5. Saeed N, Ansari HA, Khan N, Aijaz M. Disseminated cryptococcosis in an immunocompetent child. BMJ Case Rep. 2016;2016: bcr2016217195.

Publisher's Note Springer Nature remains neutral with regard to jurisdictional claims in published maps and institutional affiliations.

1 Department of Pediatrics, Dayanand Medical College and Hospital, Ludhiana Punjab India 